\title{
Educação da classe trabalhadora brasileira: expressão do desenvolvimento desigual e combinado*
}

\author{
SONIA MARIA RUMMERT \\ Universidade Federal Fluminense \\ EVELINE ALGEBAILE \\ Universidade do Estado do Rio de Janeiro \\ JAQUELINE VENTURA \\ Universidade Federal Fluminense
}

\section{INTRODUÇÃO: NOTAS SOBRE O CAPITAL- IMPERIALISMO E O DESENVOLVIMENTO DESIGUAL E COMBINADO NA ATUALIDADE BRASILEIRA}

A título introdutório, apresentamos um conjunto de reflexões sobre facetas da totalidade da qual faz parte o Brasil atual, ainda guardião de valores históricos da nossa forma particular de dominação burguesa e da mentalidade de longa duração herdada do período colonial e escravista, que, em simultâneo, busca firmar sua integração subalterna no atual cenário internacional.

* O presente texto é constituído por parte de trabalho encomendado e apresentado ao Grupo de Trabalho Trabalho e Educação, na 34a Reunião Anual da Associação Nacional de Pós-Graduação e Pesquisa em Educação (ANPEd), realizada em Natal/RN, em outubro de 2011. As reflexões incorporadas ao texto derivam de pesquisas que vêm sendo empreendidas pelas autoras com apoio da Fundação Carlos Chagas Filho de Amparo à Pesquisa do Estado do Rio de Janeiro (FAPERJ), do Conselho Nacional de Desenvolvimento Científico e Tecnológico (CNPq), da Coordenação de Aperfeiçoamento de Pessoal de Nível Superior (CAPES) e do Programa de Prociência da Universidade do Estado do Rio de Janeiro (UERJ). 
Adotamos, aqui, o conceito de "capital-imperialismo" (Fontes, 2010), por compreendê-lo como dotado de forte valor explicativo para proceder à analise da sociedade brasileira atual, particularmente em suas expressões complexas no âmbito dos processos sociais da educação e da formação humana. Corrobora nossa opção o fato de que essa abordagem não se restringe às relações econômicas stricto sensu. Ao contrário, funda-se nas "relações sociais sob o capitalismo" (idem, p. 304), compreendendo, à luz de Marx, o capitalismo como uma forma histórica de organizar a vida social, a qual impõe o "econômico como sua dimensão central, como se fosse o móvel central e o fulcro da existência humana" (idem, p. 305).

Para Virgínia Fontes (idem, p. 146), são três as características do capital-imperialismo: "o predomínio do capital monetário", 1 a "dominação da pura propriedade capitalista", bem como seu "impulso avassaladoramente expropriador", característica esta que nos interessa, particularmente, aqui. Nessa perspectiva, às desigualdades historicamente vivenciadas pela classe trabalhadora são associadas a outras e a democracia é reduzida "a um modelo censitário-autocrático, similar a assembleias de acionistas, compondo um padrão bifurcado de atuação política, altamente internacionalizado para o capital e fortemente fragmentado para o trabalho" (idem, p. 149).

O capital-imperialismo impõe à sociedade a "exigência de que toda a consciência se resuma a expandi-lo, de forma cooperativa, ou 'proativamente" (idem, p. 17), construindo-se o mosaico do senso comum (Gramsci, 1999), que se estrutura nos embates quotidianos como expressão das formas como as consciências singulares e sociais incorporam e/ou ressignificam a ideologia dominante difundida pelos múltiplos aparelhos de hegemonia (idem).

Nesse quadro, é fundamental sublinhar, como Marx e Gramsci, que um modo de produção não fica restrito à atividade econômica, mas remete, na realidade, à totalidade da vida, à produção da existência. Esse pressuposto constitui elemento fundamental quando nos debruçamos, como no caso deste trabalho, sobre as questões relativas à educação e à formação humana, forjadas na historicidade contraditória em que adquirem forma e conteúdo, predominantemente, subsumidas ao capital. Trata-se, nesse caso, de analisar elementos essenciais ao amplo e complexo processo de "produção da base social que nutre o capital" (idem, p. 42).

Hoje, o capital-imperialismo, sob a égide do capital monetário, assenta-se sobre dois mitos fundamentais: o primeiro refere-se ao fato de que é na atividade de gestão intelectual que se constrói o lucro, do qual deriva, por exemplo, o fetiche da sociedade do conhecimento; o segundo mito, que decorre do anterior, propaga a tese de que o trabalho vivo não assume mais nenhuma função relevante na vida social.

1 Com base em Marx, Fontes (2010, p. 34-35) afirma que o capital monetário "expressa e resulta da expansão do capital industrial ou funcionante e a impulsiona numa escala muito superior. [...] No momento em que o capital monetário se autonomiza perante o trabalho, se distancia dos trabalhadores concretos - aos quais segue impondo a exploração e se beneficiando da valorização que acrescentam ao trabalho morto". 
Retoma-se assim a necessidade de sublinhar a centralidade do trabalho, quando sua atual forma histórica, o sistema salarial, parece perder espaço por meio de outras formas de extração de mais-valor, que configuram a "nova morfologia do trabalho", como a denomina Ricardo Antunes (2005). Essa nova morfologia agrega as variações de precarização capazes de reduzir, ainda mais, os custos do trabalho, como por exemplo: o empreendedorismo, o cooperativismo induzido, a terceirização e a quarteirização, a subcontratação, o trabalho domiciliar, ou seja, as diferentes estratégias de expropriação dos direitos do trabalho.

$\mathrm{O}$ aspecto fundamental a assinalar aqui reside na relação estrutural, interdependente e contraditória entre o capital produtivo e o capital monetário, em que a remuneração do segundo depende, como demonstra Fontes (2010), da intensificação da extração de mais-valor do primeiro. Ao escamotear-se o fato de que é o trabalho que remunera o capital monetário, oblitera-se, por consequência, o fato de que, se por um lado, o trabalho pode prescindir do capital, por outro, não há possibilidade de que o capital, mesmo sob a forma de capital monetário, exista sem o trabalho.

O capital-imperialismo age numa perspectiva global e com referências culturais supranacionais, atuando num mundo de mercados de símbolos, coisas e seres humanos cada vez mais ampliados. Nesse cenário, as formas de intervenção nas políticas, conteúdos e métodos da educação formal se viabilizam com um alcance nunca antes atingido, do mesmo modo que se intensificam e se multiplicam as relações pedagógicas que dão contornos e conteúdos particulares a todas as facetas da formação humana. Torna-se, agora, necessário intervir com novas perspectivas, tanto sobre os diferentes aspectos da formação humana quanto, em particular, sobre a questão educacional, para simultaneamente fazer frente à superprodução acompanhada de expressiva redução da força de trabalho diretamente empregada, a drástica e sempre buscada redução dos custos do trabalho, bem como para aprofundar e intensificar as estratégias de controle social em situações de agudas formas de expropriação.

A permanente expansão e consolidação do capital-imperialismo exige a internacionalização das políticas públicas, dos processos de gestão, das regras e normas necessárias para fazer funcionar os sistemas de produção e de consumo em todo o território que atinge ou pretende atingir, de forma integrada e coadunada às necessidades do sistema produtivo total que ele próprio engendra.

Assim, a ênfase na fundamental importância da educação para a contemporaneidade capitalista constitui, na realidade, o somatório de demandas quanto à produtividade da força de trabalho que não é linear, mas fortemente marcada por um caráter seletivo e fragmentário. A tais demandas somam-se as cada vez mais intensas necessidades de controle social, derivadas diretamente da intensificação da expropriação. Tal controle busca efetivar-se tanto pela obtenção do consentimento ativo dos governados, visando a torná-los copartícipes dos processos de expropriação, quanto por meio do que denominamos de políticas de invisibilidade (Rummert, 2009), que objetivam, o mais das vezes, assegurar "lo indispensable para 
evitar la constitución de los grupos más vulnerables en emergentes contra el poder establecido" (Puiggrós; Gagliano, 2004, p. 26).

Os aspectos aqui brevemente referidos são permeados por uma necessidade imposta pelo atual estágio do conhecimento científico e tecnológico, tal como apropriado pelas forças dominantes e desigualmente disseminado de forma parcelar e fragmentária no processo de desenvolvimento desigual e combinado da socialização da produção. Defronta-se, assim, o capital-imperialismo com a necessidade de elevar o nível de subsistência da força de trabalho, bem como de fazer frente às possibilidades de desestabilização advindas dos processos de correlações de forças, o que requer permanentes estratégias de controle social. É nesse cenário do capital-imperialismo que a educação é chamada à cena, de forma recorrente, como estratégia que visa a enfrentar o estado de indeterminação da contemporaneidade.

No caso do Brasil, o capital-imperialismo assume forma e conteúdo particulares, marcados por ser o país, hoje, detentor de condições fundamentais para constituir um polo integrado subalternamente ao capital-imperialismo, entre as quais podem ser destacadas: um ciclo de industrialização do capital, contando com diferentes setores econômicos complexamente entrelaçados; "um Estado plasticamente adaptado ao fulcro central da acumulação de capitais" (Fontes, 2010, p. 307) e formas que podem ser suficientemente estáveis de contenção de manifestações reivindicativas populares e de apassivamento da classe trabalhadora. Cabe registrar, ainda, a complexificação de nosso padrão de sociabilidade, tendo em conta tanto as transformações ocorridas nas formas de lutas populares quanto nos padrões de atuação burguesa. Tal complexidade se acentua ao trazermos também para a análise as contradições de longa duração que remontam aos traços de nossa colonização ainda não superados, entre os quais se destacam a "especificidade política e o estatuto rebaixado da questão da força de trabalho, escravismo e encomiendas, que lhe confere especificidade social” (Oliveira, 2003, p. 127). É essa formação heteróclita que Francisco de Oliveira denominou "ornitorrinco".

Nesse cenário, a educação desempenha papel essencial no conjunto de estratégias de controle social do capital-imperialismo subalterno, como: a promoção de políticas de redução da pobreza da ampla massa de trabalhadores; a criação de parcerias público-privadas, entre outras "ações articuladas" com empresas, bancos e organizações empresariais e da sociedade civil para colaborar nos encaminhamentos das políticas de enfrentamento da "questão social" (Montaño, 2002).

Esse complexo entrelaçamento de ações pedagógicas, nas duas últimas décadas, vem se caracterizando por conjugar, em proporções particulares: a ênfase na educação como solução individual para a precarização da vida e para o intensificado processo de destituição de direitos; a captura de movimentos (sociais e sindicais) de organização dos trabalhadores, visando a torná-los copartícipes de sua própria condição de expropriação - pela “conversão mercantil-filantrópica” e pelo "empresariamento direto de setores populares" (Fontes, 2010, p. 347); e, ainda, pela ampliação do incentivo ao consumo, viabilizado, inclusive, pelo que Fontes (2005, 2010, p. 348) denomina de "políticas de gotejamento". Na mesma linha de 
argumentação acerca do papel anestesiador do consumo, Francisco Oliveira (2003, p. 144) afirma: "Todas as formas dos produtos da revolução molecular-digital podem chegar aos estratos mais baixos de renda". ${ }^{2} \mathrm{O}$ autor ressalta, ainda, que "essa capacidade de levar o consumo até os setores mais pobres da sociedade é ela mesma o mais poderoso narcótico social" (idem, ibidem).

A compreensão mais ampla da extensão desse processo nos é oferecida por Florestan Fernandes (2007, p. 269, grifos do original), quando analisou, ainda na década de 1970, um movimento que, depois de retração nas décadas seguintes, volta de forma acentuada na atualidade:

O crescimento econômico, o aumento de empregos, a modernização tecnológica, a elevação progressiva da renda ou dos padrões de consumo, etc., só se tornam visíveis através de símbolos internos, que são, além disso, manipulados para ofuscar a consciência crítica das classes oprimidas e ganhar a adesão das classes médias. Ela [a burguesia] projeta, desse modo, a "condição burguesa" para fora da burguesia e implanta, no coração mesmo de seus inimigos de classe, identificações e lealdades mais ou menos profundas para com o consumismo, a ordem social competitiva e o Estado democrático e nacional.

Sem superar as matrizes do desenvolvimento interno desigual e combinado e da modernização do arcaico, o bloco das burguesias no poder converge, significativamente, acerca das políticas e práticas que visam a desmontar o precário quadro de direitos sociais e políticos que vinham sendo arduamente conquistados pelos trabalhadores. Essa clara convergência incorpora interesses das diferentes frações do capital, tanto no âmbito interno quanto no internacional, entrelaçando princípios e valores das diferentes facetas do capital-imperialismo empenhadas em reduzir ao mínimo, e de forma constante, os custos do trabalho; objetivo que pautou, em larga medida, a história brasileira no que se refere à articulação Estado/burguesias.

Diferentes formas históricas de produção, das mais modernas às mais arcaicas, como manufatura, taylorismo, fordismo, além de, lamentavelmente, trabalho escravo e trabalho infantil, ainda são práticas conjugadas no presente, conjuminadas num mesmo ramo produtivo ou numa mesma empresa, associadas por vezes aos mais avançados padrões produtivos das novas tecnologias, compondo um exemplo claro de desenvolvimento desigual e combinado, típico do capital-imperialismo mundial e agudizado em países integrados de forma subordinada, como é o caso do Brasil. Ao contrário da abordagem "etapista" que caracteriza análises oficiais no âmbito econômico e educacional, os novos momentos históricos do trabalho não elidem os precedentes, não prescindem deles e até os fomentam, incorporando-os para a

2 Podemos citar, a título de ilustração, dados da Anatel indicando que o Brasil terminou o $1^{\text {o }}$ semestre de 2011 com 217,3 milhões de celulares e uma densidade de 111 celulares para cada 100 habitantes, conforme divulgado por Lemos (Fachin, 2011). O mesmo autor ainda assinala que "109 mil lan houses existentes no país contrastam com 2,5 mil salas de cinema, 5 mil bibliotecas públicas ou 2,6 mil livrarias” (idem). 
consecução de suas metas como ocorre, na atualidade, com a parcela da produção de natureza intelectual, flexível, integrada, polivalente, para a qual as formas supostamente superadas de trabalho são dotadas de funcionalidade essencial para o capital.

Tais considerações sobre as relações capital e trabalho no Brasil, ao longo de sua formação sócio-histórica, nos levam a reconhecer que a análise de Florestan Fernandes sobre a modernização da economia agrária pode e deve ser estendida a toda a nossa formação econômica. Para o sociólogo, essa modernização não foi "em si e por si mesma fator de mudança estrutural da situação ou de superação efetiva das iniquidades socioeconômicas, sociais e políticas. Com frequência ela se opera sem afetar profundamente a concentração social da renda e do poder" (Fernandes, 2008, p. 188).

Segundo nosso entendimento, é à luz do referencial anteriormente referido que se torna possível compreender, para além da aparência, o efetivo sentido e a funcionalidade do compósito constituído, na atualidade brasileira, por expressivo conjunto de iniciativas voltadas para a educação e formação da classe trabalhadora no país. Com o fito de proceder à análise aqui proposta, após essa introdução em que tecemos algumas considerações de caráter conceitual, discutiremos a nova configuração da dualidade educacional no país, apresentando as relações entre o cenário do capital-imperialismo subalterno e as novas formas de destituição do direito de acesso universal às bases do conhecimento científico e tecnológico. A seguir, abordaremos o conjunto de programas e ações empreendidos pelo governo federal a partir da década de 1990, apresentando-os reunidos segundo características que identificamos portadoras de similitudes, como será explicitado na terceira parte do artigo, visando a esclarecer nossa perspectiva de análise.

\section{A FORMA HISTÓRICA DE DESENVOLVIMENTO DESIGUAL E COMBINADO NA EDUCAÇÃO ESCOLAR, OU A DUALIDADE EDUCACIONAL DE NOVO TIPO}

Nas últimas duas décadas, uma das fortes e primeiras adesões às diretivas internacionais no campo educacional, precedendo nisso o Estado, foi a da burguesia industrial nos anos de 1990 (Rodrigues, 1998; Rummert, 2000). Na linha propositiva e de intervenção da qual não se afastou nos anos subsequentes, e coerentemente com as diretrizes formuladas para a educação da classe trabalhadora no âmbito do capital-imperialismo, a Confederação Nacional da Indústria (CNI) enfatiza, atualmente, o caráter comportamental a ser priorizado na educação, em detrimento da apropriação das bases do conhecimento científico e tecnológico, tendo em vista a empregabilidade dos trabalhadores: "São valorizadas competências que vão além dos conhecimentos científicos e tecnológicos e incluem habilidades básicas, específicas e de gestão, atitudes relacionadas à iniciativa, criatividade, solução de problemas e autonomia" (CNI, 2005, p. 33).

A ideia de empregabilidade associada a uma demanda particular de qualificação da força de trabalho encobre a teia da expropriação dos direitos do trabalho 
que para a CNI é apresentada como a importância de "contar com mão de obra qualificada e com um sistema mais flexivel de negociação no mercado de trabalbo" (CNI, 2005, p. 63, grifos nossos). Não divergem dessa perspectiva os argumentos que visam a reduzir ao máximo os custos do trabalho, corroendo seu estatuto. Nesse caso, trata-se de

Promover a cultura empreendedora na educação [o que] significa desenvolver valores para criar a prática de comportamentos individuais na busca de soluções e iniciativas na gestão do próprio negócio, na participação e organização das formas de geração de renda e emprego e na condição de cidadão ativo, como empreendedor social. (idem, p. 34$)^{3}$

$\mathrm{Na}$ atual forma histórica de dualidade educacional, o elemento novo é constituído pelas ofertas educativas que propiciam possibilidades de acesso a diferentes níveis de certificação, falsamente apresentados como portadores de qualidade social igual a das certificações às quais têm acesso as burguesias. Obscurece-se assim, cada vez mais, o fato de que não há, efetivamente, ações destinadas à elevação igualitária do nível educacional da classe trabalhadora em sua totalidade.

Se, por um lado, a dualidade educacional se mantém, posto ser expressão da dualidade estrutural fundante do modo de produção capitalista, por outro, assume diferentes formas históricas. Mario Manacorda nos ensina que a essência da oposição reside no binômio escola/não escola e, recorrendo metaforicamente a Marx, afirma: "para usar uma expressão quase marxiana, a escola se coloca frente ao trabalho como não trabalho e o trabalho como não escola" (Manacorda, 1991, p. 116). Essa oposição de base se metamorfoseia ao longo da história brasileira, assumindo diferentes contornos: inicialmente, a ausência efetiva de acesso à escola para a maioria da classe trabalhadora; a seguir, as ofertas formalmente diferenciadas de percursos escolares para as burguesias e para a classe trabalhadora. Atualmente se verifica a democratização de acesso a todos os níveis de certificação, mantendo-se a diferença qualitativa entre os percursos da classe trabalhadora e os das classes dominantes, como será explicitado adiante.

Nesse sentido, não é demais relembrar a visão de Suchodolski (2010, p. 60) acerca do sentido de hegemonia da educação nos marcos do capitalismo:

O caráter de classe da educação burguesa manifesta-se num duplo aspecto. Em primeiro lugar, pelo fato de que a educação, que supostamente deveria servir todos os homens, só é concedida aos filhos da burguesia. A educação não é um ele-

3 Ainda no mesmo documento, a CNI estabelece parâmetros que considera "necessários" como metas para o ano de 2015 (admitindo, como aceitáveis, significativos padrões de destituição de direitos, como o do saneamento ou de acesso à internet). Entre eles, destacamos os seguintes indicadores: "Domicílios atendidos por Rede Coletora de Esgoto: 70\%"; "Domicílios com acesso à Internet: 30\%"; "Pisa - alcançar a nota 486 (Espanha 2001)"; “Taxa de desemprego: 6\%” (CNI, 2005, p. 18). 
mento de igualdade social; é, pelo contrário, um elemento de hierarquia social burguesa moderna. Em segundo lugar, o caráter de classe do ensino burguês manifesta-se ao transformar o ensino num instrumento supostamente eficaz da "renovação social". Em todas as ocasiões em que a burguesia se vê forçada a reconhecer que as relações capitalistas são inadequadas, tenta demonstrar com "argumentos educativos" que são inadequadas, porque os homens não são bons e que estas relações melhorarão quando os homens se tornarem melhores.

Associando-se o paradigma econômico - definido pela posição do Brasil na condição de integração subalterna no capital-imperialismo -, à demanda social, em parte gerada pela difusão midiática das teses do capital humano, é criada uma miríade de ofertas de elevação de escolaridade/formação profissional/certificação. A multiplicidade, desordenada, flácida e de difícil acompanhamento e controle, mergulha a totalidade social na fantasia de que a efetiva democracia chegou à educação escolar, como se fosse factível construí-la "pelo alto" (Coutinho, 1984) e tão somente no âmbito educacional. Retoma-se assim, sobre novas bases, a antiga marca social da escola que Gramsci (2000b) identificou, ainda nos anos 1930, ao analisar a ampliação artificial das possibilidades de formação profissional na Itália.

As significativas cisões que atravessam a educação no país encobrem, sob a forma de múltiplas e renovadas possibilidades, o que permanece constante: a ausência de compromissos efetivos do Estado, tal como compreendido por Gramsci (1999, 2000a), com a garantia de acesso igualitário às bases do conhecimento científico e tecnológico. Tais cisões não se assentam mais no binômio ingresso/não ingresso na escola, mas no ingresso em vias formativas diferenciadas que, também de forma desigual e combinada, visam a tornar mais próxima a universalização de índices de escolaridade sem universalizar condições de permanência e sucesso nem padrões socialmente referenciados de qualidade pedagógica. É a esse novo formato de destituição de direitos no âmbito educativo que denominamos de dualidade educacional de novo tipo.

Esse quadro compósito, bem como sua funcionalidade à integração subalterna ao capital-imperialismo, coaduna-se tanto com as características fortemente fragmentadas do trabalho no atual estágio de expansão e consolidação do capital, quanto com as marcas particulares do país ornitorrinco. Não é outra a imagem a associar à educação brasileira, que na ausência de um sistema nacional de educação que a organize de forma unitária é marcada pela intensa fragmentação e multiplicidade de vertentes formativas.

Verifica-se, assim, a manutenção da desigualdade no próprio processo de democratização da escola. Ocorrem mudanças nas condições de permanência, de acesso ao conhecimento e de obtenção de certificação, mas elas se dão como um modo particular de produção de uma dualidade de novo tipo, que se expressa, entre outros aspectos, nas distinções entre as redes municipais, estaduais e federal, e, no seu interior, entre os vários modelos e modalidades; nos variados padrões de oferta das redes privadas; na multiplicidade de oportunidades formativas que recriam ou 
instituem trajetórias subordinadas de formação, as quais, em conjunto, ressignificam a marca social da escola, cujo caráter classista é encoberto pelo discurso inclusivo.

\section{AS MÚLTIPLAS OFERTAS E SEU CARÁTER PULVERIZADO, DESIGUAL, IRREGULAR E INSTÁVEL}

A análise dos programas instituídos desde os anos iniciais da década de 1990, nos variados setores de ação governamental envolvidos com algum tipo de "projeto social", ${ }^{4}$ é extremamente reveladora desse novo quadro geral de oferta educacional que simultaneamente expressa e produz novas formas e condições de formação humana em curso. Trata-se de um emaranhado de ações dirigidas aos mais diferentes propósitos (financiamento de ações regulares, ajustes institucionais, ampliação ou reforma infraestrutural, formação funcional, indução de políticas, entre outras), no interior do qual se destacam, por sua quantidade e variedade, programas nitidamente dirigidos à formação de crianças, adolescentes, jovens e adultos denominados como pobres, ou seja, aqueles expropriados do próprio direito à vida, num patamar mínimo de dignidade.

Uma questão central a ressaltar aqui é que quantidade e variedade não significam oferta ampla, mas sim pulverizada, desigual, irregular e instável. Isso se evidencia, entre outros aspectos, no perfil formativo dos variados programas, ${ }^{5}$ que pode pender para a reinserção escolar, a complementação da escolaridade, a qualificação profissional, a formação cívica ou a formação atitudinal, entre outros vieses formativos cujos sentidos verdadeiros só são apreensíveis se levarmos em conta o efeito de conjunto dessa variedade de ações instáveis e orgânicas à lógica da forte fragmentação do trabalho e do imprescindível controle social.

Entre os programas instituídos no período anteriormente indicado, é possível reconhecer, apenas na esfera federal, cerca de trinta, cujo perfil e forma de realização

4 Além do Ministério da Educação, destacam-se na proposição de programas formativos, outros ministérios, como o do Desenvolvimento Agrário (MDA), o de Trabalho e Emprego (MTE), Justiça (MJ), Saúde (MS) etc.; além de secretarias e órgãos variados com status de ministério.

5 Além das diferenças de perfis entre programas, deve-se observar as variações de perfis de cada programa ao longo dos processos de sua implementação, seja em decorrência de ajustes relacionados a mudanças no alcance populacional previsto, de alterações dos setores responsáveis por sua execução ou, ainda, de fusões e incorporações entre programas, entre outras causas. O rastreamento dessas mudanças, por sua vez, é extremamente dificultado não apenas pelo grande número de medidas normativas que se sucedem ao longo da vigência dos mesmos, mas por causa também da existência de medidas que em certos momentos tratam de diversos programas ao mesmo tempo, bem como das remissões legislativas que implicam definições complementares às informações constantes nas medidas normativas originais. Isso inviabilizou, nos limites deste artigo, a apresentação de todas as referências normativas dos programas apresentados, bem como o detalhamento das alterações de perfil e denominação destes, obrigando a nos atermos ao mínimo possível de informações. 
incidem claramente na instituição de vias formativas diferenciadas e efetivamente não equivalentes. Sua agregação, conforme o perfil da formação oficialmente anunciada, revela aspectos importantes da realidade social a cuja inclusão periférica de alguns tais programas parecem se dirigir.

Sem omitirmos as dificuldades dessa agregação e seu inevitável caráter arbitrário, tendo em vista que uma de suas fortes marcas é uma espécie de polivalência funcional, propomos reuni-los em três grandes categorias, definidas pelos ramos de escolarização que eles parecem instituir ou consolidar: programas dirigidos à ampliação do ingresso, reinserção, permanência e conclusão da escolarização regular obrigatória; cursos e programas dirigidos à ampliação da escolaridade de jovens e adultos; programas de financiamento educacional.

\section{A ESCOLARIZAÇÃO REGULAR OBRIGATÓRIA PARA CRIANÇAS E ADOLESCENTES DA CLASSE TRABALHADORA}

O primeiro conjunto diz respeito a programas dirigidos à ampliação do ingresso, reinserção, permanência e conclusão da escolarização regular obrigatória, observando-se, nesse caso, pelo menos três tipos de programas, que parecem cumprir funções complementares: aqueles cuja ênfase é a inserção, reinserção e permanência na escola, por meio da vinculação entre escolarização e concessão de renda mínima, como o Programa de Erradicação do Trabalho Infantil (PETI) e o Bolsa Escola Federal, ${ }^{7}$ posteriormente anexados ao Bolsa Família; ${ }^{8}$ os que se destinam à ampliação da jornada escolar, tais como o Segundo Tempo e o Mais Educação; ${ }^{10}$ e os que promovem a permanência e a conclusão do ensino fundamental por meio da aceleração do processo de escolarização no interior da própria educação regular, sob a forma de programas de aceleração de aprendizagem. ${ }^{11}$

6 Programa de renda mínima vinculado à escolarização de crianças e adolescentes submetidos a trabalho infantil penoso, insalubre e degradante. Iniciado em 1996 e integrado, em 2005, ao Programa Bolsa Família.

7 Criado em 1998, com o nome de Programa de Garantia de Renda Mínima (PGRM), em 2001 foi modificado e ampliado, passando a denominar-se Programa de Garantia de Renda Mínima Vinculada à Educação - Bolsa Escola. Em 2004 foi incorporado ao Programa Bolsa Família.

8 Instituído por meio da medida provisória n. 132/2003 como um programa unificado de transferência de renda com condicionalidades, agregando diversos programas de renda mínima instituídos nas gestões de Fernando Henrique Cardoso.

9 Criado pela portaria interministerial n. 3.497/2003, refere-se a um programa de extensão de jornada escolar, por meio da oferta de formação e práticas esportivas no contraturno escolar.

10 Instituído pela portaria interministerial n. 17/2007, na forma de um programa de ampliação da jornada escolar, por meio do fomento à realização de atividades socioeducativas no contraturno escolar.

11 Realizados a partir de 1995, tais programas foram criados com o objetivo de "correção do fluxo escolar" por meio da oferta de parte da escolarização fundamental regular em classes com duração diferenciada, para alunos em situação de distorção idade-série. 
Tais programas, frequentemente discutidos por seus efeitos quanto à ampliação das taxas de ingresso, permanência e conclusão da escolarização obrigatória, vêm inegavelmente instituindo vias formativas distintas dentro da própria educação regular, não apenas em virtude das diferentes composições curriculares que induzem ou estabelecem, mas também em decorrência das diferentes condições e dinâmicas de formação escolar que resultam das formas específicas como são organizados e executados.

Aspectos importantes a se destacar, nesse caso, são seus diferentes parâmetros de duração das jornadas diárias, dos períodos e das etapas de formação escolar; seus diferentes critérios e formas de composição dos corpos profissionais envolvidos com a ação escolar; seus distintos regimes e condições de trabalho para a atuação profissional na área. Além disso, tais programas geralmente possuem especificidades também quanto às tarefas de coordenação pedagógica; aos calendários; aos mecanismos de gestão, supervisão e prestação de contas (como nos casos das formas de acompanhamento e registro da frequência e do desempenho); às prescrições sobre as relações entre a instituição escolar e as famílias dos alunos; e aos critérios adotados para a constituição das turmas (especialmente no caso dos programas de aceleração de aprendizagem). Essas características não apenas implicam relevantes diferenças nas trajetórias escolares e nas experiências de escolarização, como também concorrem para a produção de novas formas de desgaste e precarização da escola, em virtude da sobreposição e sobrecarga de tarefas e funções, bem como das permanentes mutações dos usos das instalações escolares, da ação escolar e do próprio trabalho docente (Algebaile, 2009).

\section{A EDUCAÇÃO DE JOVENS E ADULTOS TRABALHADORES}

Um segundo agrupamento pode ser feito em relação a cursos e programas dirigidos à ampliação da escolaridade de jovens e adultos. Consideramos, nesse caso, as ações que enfatizam o ingresso ou o retorno à escolarização básica articulada ou não à educação profissional, em propostas formativas de caráter suplementar dirigidas aos que não concluíram as etapas do ensino fundamental e médio na idade própria. Esse grupo envolve a oferta de cursos e exames de educação de jovens e adultos (EJA) pelos sistemas estaduais e municipais de ensino, bem como variados programas governamentais voltados à realização de processos formativos com durações e conteúdos diversos. Destacam-se aqui os programas criados pelo governo federal, ligados à Presidência da República ou a ministérios, envolvendo: cursos de alfabetização, como os realizados pelos Programas Alfabetização Solidária ${ }^{12} \mathrm{e}$ Brasil Alfabetizado; ${ }^{13}$ de educação geral e formação profissional inicial, vinculados

12 Criado em 1997, no âmbito do Programa Comunidade Solidária, responsável, no governo de Fernando Henrique Cardoso, pela realização de parte significativa de programas sociais de caráter emergencial, por meio de parcerias com a sociedade civil.

13 Criado no início da primeira gestão presidencial de Luiz Inácio Lula da Silva, pelo decreto n. 4.834/2003, e reorganizado pelo decreto n. 6.093/2007. 
à concessão de renda mínima por período determinado, como o Agente Jovem ${ }^{14} \mathrm{e}$ o Programa Nacional de Inclusão de Jovens (PROJOVEM); ${ }^{15}$ de formação geral e profissional sem vínculo com renda mínima, como o Programa Nacional de Integração da Educação Profissional com a Educação Básica na Modalidade de Educação de Jovens e Adultos (PROEJA); ${ }^{16}$ de ampliação da escolarização de profissionais de áreas específicas, como o Projeto de Profissionalização dos Trabalhadores da Área de Enfermagem (PROFAE) ${ }^{17}$ e o Programa Nacional de Educação na Reforma Agrária (PRONERA); ${ }^{18}$ além dos novos sistemas de exames com certificação - Exame Nacional de Certificação de Competências de Jovens e Adultos $(\text { ENCCEJA })^{19}$ e Rede Nacional de Certificação Profissional e Formação Inicial e

14 Instituído em 2000, foi originalmente criado como um programa de renda mínima vinculado à escolarização e à formação para a atuação comunitária e a inserção laboral de jovens em situação de vulnerabilidade e risco social, na faixa etária de 15 a 17 anos; foi sucessivamente modificado e, em 2007, incorporado ao PROJOVEM.

15 Originalmente instituído em 2005, na forma de um programa que vinculava concessão de renda por tempo determinado e formação com vistas à complementação de escolaridade e preparação para a inserção laboral, para jovens na faixa etária de 18 a 24 anos. Em 2008, foi subdividido em quatro modalidades: PROJOVEM Urbano, PROJOVEM Trabalhador, PROJOVEM Adolescente e PROJOVEM Campo - Saberes da Terra, que incorporaram programas preexistentes como Escola de Fábrica, Agente Jovem e Saberes da Terra. A faixa etária atendida também foi expandida, em alguns casos, para os limites de 15 e de 29 anos.

16 Instituído em 2005, o PROEJA foi inicialmente concebido como um programa de ampliação da escolaridade correspondente ao ensino médio, articulada à educação profissional, com realização circunscrita às instituições federais de educação tecnológica. Um ano depois, porém, foi modificado pelo decreto n. 5.840/2006, mantendo-se a sigla, mas alterando-se sua abrangência e denominação. Segundo o novo perfil, o Programa Nacional de Integração da Educação Profissional com a Educação Básica na Modalidade de Educação de Jovens e Adultos (grifos nossos) passou a envolver cursos de formação inicial e continuada, vinculados à elevação da escolaridade correspondente ao ensino fundamental. A partir de 2009, o eixo relacionado à formação inicial e continuada vinculada ao ensino fundamental passou a ser denominado PROEJA FIC, definindo-se meios e procedimentos específicos para sua implantação nos municípios e nos estabelecimentos penais.

17 Criado no âmbito do Ministério da Saúde por meio da portaria n. 1.262/1999, o PROFAE envolveu a realização de variados cursos destinados à ampliação da qualificação dos profissionais da área de enfermagem, de diferentes níveis e com diferentes durações, incluindo complementação de ensino fundamental na forma de cursos supletivos com duração máxima de 18 meses.

18 Criado por meio da portaria n. 10/1998, o PRONERA abrange cursos de alfabetização, educação básica e profissional e formação de professores nas regiões de acampamentos e assentamentos rurais.

19 Instituído por meio da portaria n. 2.000/2002, o ENCCEJA foi concebido como um instrumento de avaliação destinado à certificação de competências e habilidades de jovens e adultos em nível do ensino fundamental e médio, sendo realizado anualmente pelo Instituto Nacional de Estudos e Pesquisas Educacionais Anísio Teixeira (INEP) desde 2003, na forma de um exame nacional a cuja realização as secretarias estaduais e municipais de educação podem aderir. 
Continuada (Rede CERTIFIC). ${ }^{20}$ Algumas ações vinculadas ao Plano Nacional de Educação Profissional (PLANFOR) ${ }^{21}$ (1995-2003) - e ao Plano Nacional de Qualificação (PNQ22 (2003) - devem também ser consideradas nesse agrupamento, já que em seu âmbito observa-se a progressiva presença de indicações relativas à integração entre a qualificação profissional e as estratégias de elevação de escolaridade relacionada à alfabetização e à educação fundamental e média.

Essa política de EJA pulverizada - gestada por meio de programas e projetos, e realizada mediante a adesão dos estados e municípios ou pela instituição de parcerias público-privado, por sua vez induzidas por pressões diretas do governo federal ou pelas vantagens que proporcionam, especialmente pelos recursos disponibilizados - vem gerando uma intensa diferenciação interna da própria EJA, que, desde a década de 1990, adquiriu uma "nova" identidade, muito mais fragmentada, heterogênea e complexa (Ventura, 2008). Essa multiplicidade de iniciativas converge para uma configuração multifacetada da formação de jovens e adultos, em decorrência da diversidade de vínculos institucionais, de instalações, recursos, equipes profissionais, durações e perfis formativos que passam a caracterizar os cursos oferecidos a públicos-alvo cada vez mais segmentados, seja em razão de sua inscrição territorial (urbana, urbano-metropolitana, agrária, área de concentração de pobreza etc.), de seu pertencimento étnico-cultural (indígenas, quilombolas), ou de sua situação de participação econômica e social (situações de risco, vulnerabilidade, exposição à violência, desemprego), entre outros aspectos.

Parte significativa dos programas aí envolvidos é fortemente marcada pela instabilidade, tanto por sua incerta duração quanto por seus distintos padrões de organização, implicados com pouca precisão sobre seus vínculos institucionais reais. Outro aspecto a ressaltar é o viés comportamentalista de muitos programas, que, apesar de enfatizarem a qualificação profissional básica vinculada à ampliação de escolaridade, não raramente apresentam um confuso delineamento formativo, que pode envolver apelos ao civismo, ao suposto protagonismo juvenil, ao engajamento comunitário, ao combate à violência, ao empreendedorismo, à preservação ambiental ou aos cuidados com a saúde etc. Por fim, cabe considerar também que esses programas competem entre si e com a escola pública (mesmo quando ocupam suas instalações) e, com frequência, esvaziam ou inibem a própria expansão das matrículas de educação regular.

20 A portaria interministerial n. 1.082/2009 dispõe sobre a criação da Rede CERTIFIC, que constitui "uma Política Pública de Educação Profissional e Tecnológica voltada para o atendimento de trabalhadores, jovens e adultos que buscam o reconhecimento e certificação de saberes adquiridos em processos formais e não formais de ensino-aprendizagem e formação inicial e continuada”.

21 Delineado a partir de 1995, no âmbito da Secretaria de Formação e Desenvolvimento Profissional (SEFOR), do Ministério do Trabalho, o PLANFỎR foi concebido como um conjunto de ações de qualificação e requalificação profissional a serem executadas com recursos do Fundo de Amparo ao Trabalhador (FAT).

22 Instituído pela resolução n. 333/2003, do CODEFAT, e reformulado por sucessivas medidas, o PNQ envolve ações de qualificação social e profissional vinculadas a Planos Territoriais, Especiais e Setoriais de Qualificação. 


\section{O FINANCIAMENTO DA FORMAÇÃO PROFISSIONAL DA CLASSE TRABALHADORA}

Complementando o cenário da educação obrigatória regular internamente ramificada e da EJA multifacetada, é possível identificar um terceiro conjunto, constituído por programas de financiamento educacional que vêm influindo significativamente na expansão de vagas e na multiplicação de vias formativas no ensino médio, na educação profissional e no ensino superior. Destacam-se, nesse caso, o Fundo de Financiamento ao Estudante do Ensino Superior (FIES) (1999)23 e o Programa Universidade para Todos (PROUNI ${ }^{24}$ - ambos voltados à concessão de crédito estudantil para ingresso em instituições privadas de ensino superior -, bem como o recentemente criado Programa Nacional de Acesso ao Ensino Técnico e Emprego (PRONATEC) (2011) ${ }^{25}$, cujo objetivo manifesto - de "expandir, interiorizar e democratizar a oferta de cursos técnicos e profissionais de nível médio, e de cursos de formação inicial e continuada para trabalhadores" $-{ }^{26}$ é sustentado por um conjunto variado de ações que envolve desde o financiamento direto da expansão da oferta de educação profissional e tecnológica (EPT), por diferentes meios, incluindo cursos a distância, até a ampliação do financiamento estudantil em instituições públicas e privadas, também por meios variados.

Esses programas, apesar de seu menor número, apresentam repercussões importantes por sua escala de realização e por seus efeitos na reconfiguração da demanda e da oferta de educação profissional, média e superior. Parte relevante dessa reconfiguração resulta da indução sistemática, por eles promovida, da procura de vagas em instituições privadas, por parte de segmentos sociais de baixa renda, e o efeito direto dessa indução de demanda é a constituição, em larga escala, de um novo e lucrativo eixo de expansão da oferta privada. Por essas características, os programas que integram esse grupo concorrem para configurar, juntamente com os grupos anteriormente explicitados, o que denominamos como dualidade educacional de novo tipo.

23 Criado pela medida provisória n. 1.827-1/1999, reeditada 27 vezes, até ser convertida na lei n. 10.260/2001, o FIES é um programa do MEC destinado inicialmente a financiar prioritariamente estudantes de cursos de graduação em instituições privadas, tendo sido ampliado posteriormente, pela lei n. 12.202/2010, para o financiamento de educação profissional técnica de nível médio.

24 Instituído pela medida provisória n. 213/2004, convertida na lei n. 11.096/2005, o PROUNI é um programa de concessão de bolsas de estudos a estudantes de cursos de graduação e de cursos sequenciais de formação específica em instituições privadas de educação superior, envolvendo isenção de tributos às instituições que a ele aderem.

25 Instituído pela lei n. 12.513/2011, o PRONATEC é um programa de financiamento da expansão e interiorização da oferta de cursos de educação profissional e tecnológica, organizando-se por meio de subprogramas, projetos e ações de assistência técnica e financeira, envolvendo a realização de ações diretas de expansão da rede federal de educação profissional, o financiamento da expansão das redes estaduais, bem como a concessão de bolsas e o fomento à expansão da rede de atendimento dos serviços nacionais de aprendizagem e da educação a distância, entre outros aspectos.

26 Disponível em: <http://www.brasil.gov.br/sobre/educacao/ensino-tecnico/como-ingre ssar/pronatec $>$. Acesso em: mar. 2012. 
As ações de (con)formação da classe trabalhadora não se esgotam, entretanto, nessa tipificação aqui apresentada. Às margens das ações voltadas para a expansão da certificação correspondente à educação obrigatória, é possível identificar mais um conjunto de programas que, apesar da grande diversidade, podem ser agregados em decorrência de duas características principais: a ausência de vínculos com a ampliação da escolaridade ou sua posição secundária no desenho geral do programa; e a ênfase em objetivos formativos variados, cujas adjetivações não chegam a disfarçar a preocupação central de controle social sobre as frações da classe trabalhadora para as quais não está prevista uma efetiva participação nas formas mais institucionalizadas de atuação econômica, política e social, mas sim o gerenciamento da pobreza extrema a qual estão submetidas.

A identificação desses programas é complexa, pois, em muitos casos, eles são definidos como linhas de ação que integram programas maiores, cujos nomes não denunciam de imediato seu caráter de hospedeiros de medidas focais. Seu perfil também é muito diversificado, resultando, geralmente, de variadas composições entre qualificação profissional, capacitação para o desenvolvimento de empreendimentos produtivos específicos, formação orientada para o empreendedorismo e formação orientada para a atuação comunitária. Em alguns casos, tomam a forma de cursos associados a medidas de inserção laboral, concessão de renda mínima por tempo determinado ou concessão de microcrédito. Entre os programas de concessão de renda mínima, alguns têm sua parte formativa limitada a preocupações com a contenção de problemas e conflitos em áreas de intensa pobreza, sendo definidos como programas orientados ao combate à violência, à reinserção social de detentos e jovens em cumprimento de medidas de privação de liberdade, à proteção em relação ao aliciamento pelo crime, entre outros vieses.

Apresentando nomes por si reveladores de seus propósitos político-ideológicos - Juventude Cidadã, ${ }^{27}$ Soldado Cidadão, ${ }^{28}$ Reservista Cidadão, Mães da Paz, Projeto de Proteção dos Jovens em Território Vulnerável (PROTEJO), ${ }^{29}$ Inserção Social por Meio da Produção de Material Esportivo (Pintando a

27 Integrante do Programa Nacional do Primeiro Emprego (PNPE, iniciado em 2003 e extinto pela mesma medida provisória que criou o PROJOVEM), o projeto Juventude Cidadã resultou da reformulação do Serviço Civil Voluntário, criado em 1998, no âmbito do PLANFOR. Trata-se de projeto voltado à qualificação profissional de jovens de 16 a 24 anos considerados em situação de risco, com prioridade para o atendimento a jovens oriundos do sistema penal ou de medidas socioeducativas. No decreto de 2008 que regulamentou a reformulação do PROJOVEM, aparece incorporado como submodalidade do PROJOVEM Trabalhador.

28 Projeto criado em 2002, pelo Ministério do Trabalho em parceria com o Ministério da Defesa, com o objetivo de oferecer cursos de qualificação profissional para militares temporários egressos das Forças Armadas.

29 Vinculados ao Programa Nacional de Segurança Pública com Cidadania (PRONASCI), criado pela medida provisória n. 384/2007, convertida na lei n. 11.530/2007, os projetos Reservista Cidadão e PROTEJO foram instituídos pela mesma medida provisória que criou o PRONASCI. 
Liberdade), ${ }^{30}$ Mulheres $\mathrm{Mil}^{31}$-, são, muitas vezes, projetos ou ações indutores de atitudes que favoreçam a vinculação de segmentos sociais segregados a formas fronteiriças e residuais de trabalho, bem como sua acomodação, de modo útil, à chamada convivência comunitária. Desse modo, configura-se uma espécie de assistencialização da formação profissional para as frações da classe trabalhadora mais expropriadas $\mathrm{e}$, por isso, mais precarizadas.

Algumas características presentes em parte relevante dos variados programas até aqui apresentados merecem observações específicas. O primeiro aspecto a destacar, nesse caso, diz respeito à grande quantidade de programas formativos vinculados à concessão de renda mínima e, ainda que em menor quantidade, ao microcrédito associado ao desenvolvimento de empreendimento produtivo e ao financiamento de vagas em instituições privadas. Trata-se de um aspecto indicativo, a nosso ver, das funções que estão sendo assumidas pelos programas de renda e financiamento associados à formação, ou, mais especificamente, a qualquer formação.

Considerando-se que sua emergência e expansão sistemática vêm se dando há duas décadas, e que essa duração desautoriza sua definição como transitórios, cabe reconhecer que, do ponto de vista dos efeitos sociais esperados, esses programas estão cumprindo funções de acomodação social e econômica de uma força de trabalho para a qual a inserção laboral efetiva não está prevista. Parece-nos que a variedade de vieses formativos, nesse caso, não está associada às possibilidades concretas de inserção laboral imediata ou futura, a não ser como efeito residual. Há indicações suficientes para reconhecermos que a profusão de processos formativos em curso está, ao menos em parte, a serviço da dissimulação da impossibilidade de inserção social por outras vias que não a via de pertencimento temporário a algum programa. $\mathrm{O}$ fato de serem organizados como programas formativos, em vários casos, parece apenas disfarçar o fato de que eles não são um meio efetivo para uma forma diferenciada de inserção futura. Constituem, na realidade, um fim em si mesmos: a inserção possivel no atual contexto de expropriação no âmbito do capital-imperialismo.

Essa não é, porém, sua única função, sendo igualmente importante observar que sua quantidade, seu permanente movimento de expansão e multiplicação e sua disseminação por tantos órgãos, setores, organizações e níveis governamentais

30 Projeto que originalmente integrava um programa multissetorial coordenado pelo Ministério da Justiça e que, em 2004, foi incorporado pelo Ministério dos Esportes. Destina-se à ressocialização e profissionalização de internos no sistema penitenciário, por meio de sua atuação na fabricação de material esportivo, proporcionando-lhes renda e possibilidade de redução da pena. Atualmente, desdobra-se em dois outros projetos, de perfil similar: Pintando a Esperança e Pintando a Cidadania.

31 Implantado inicialmente em 2007 e transformado, em 2011, em ação regular integrante do Plano Brasil sem Miséria, normatizado pela portaria n. 1.015/2011, do MEC. Envolve cursos profissionalizantes que podem ser realizados por instituições diversas, incluindo as do Sistema $\mathrm{S}$ e instituições privadas sem fins lucrativos, sendo indicada a possibilidade de sua articulação com o ensino fundamental e médio. 
indicam a criação e consolidação de um novo e poderoso circuito de circulação do fundo público, por meio do financiamento de projetos que, não subordinados a regras de realização e de aplicação financeira de políticas sociais, como a educação e a saúde, possibilitam uma grande liberdade na constituição de equipes de trabalho, na contratação de consultorias, na organização de eixos de atividade de acordo com interesses corporativos, entre outras possibilidades que parecem indicar importantes nexos entre esses programas e a instauração de um novo eixo de expansão produtiva (Frigotto, 1984) da formação intra e paraescolar.

Um segundo aspecto a ressaltar é relativo à grande quantidade de programas que não dispõem de bases institucionais próprias para realizar o processo formativo anunciado, supondo a utilização da infraestrutura instalada de diferentes setores de ação do Estado. Isso vem ocorrendo, particularmente, com o setor educacional, resultando em sobrecargas de gestão administrativa e de utilização das suas instalações e recursos materiais; em perda de capacidade de acompanhamento da realização financeira dos sistemas, redes e estabelecimentos que passam a abrigar os novos programas; e em desorientação dos usuários dos programas cujos espaços de funcionamento não coincidem com as instituições às quais se vinculam. Essa ausência de bases institucionais próprias implica inúmeros problemas relacionados à constituição das equipes funcionais encarregadas de sua coordenação e execução, sendo frequente o deslocamento de profissionais de suas funções originais para atuarem temporária ou permanentemente nas novas atividades, bem como a constituição de equipes segundo critérios de contratação e regimes de trabalho diferenciados dos estabelecidos para a composição do corpo de funcionários da educação regular e das modalidades de escolarização consolidadas na legislação educacional.

Por fim, devem-se observar as incidências desses programas na instituição de novas formas de categorização dos segmentos sociais que constituem seus públicos-alvo. A análise dos documentos que normatizam sua criação, reformulação, desmembramento ou agregação ao longo das duas décadas consideradas neste trabalho mostra que as categorizações iniciais de público-alvo, referidas principalmente às situaçôes laborais - de emprego, desemprego ou ocupação instável - vêm gradualmente cedendo espaço a categorizações cada vez mais referenciadas na multiplicidade de situaçôes assistenciais não laborais vinculadas à condição de egresso ou beneficiário de algum programa precedente, bem como a variadas situações de vida identificadas como de vulnerabilidade e risco social.

A comparação dessas novas categorizações com as formas clássicas de definição de sujeitos de políticas públicas orientadas pelo princípio da universalização - como as referências etárias, de etnia e gênero - é igualmente reveladora das novas classificações sociais, que, longe de nomearem sujeitos de direitos, parecem listar objetos de ação definidos em conformidade com as mais diversas situações de destituição de direitos, assistidas ou não, derivadas do cenário aqui delineado. 


\section{CONCLUSÃO}

A compreensão do quadro multifacetado da educação e da formação da classe trabalhadora no Brasil requer que o relacionemos com as características da integração subalterna do Brasil no cenário capital-imperialista, com nossas marcas de sociedade ornitorrinco. Tal relacionamento não implica, entretanto, ignorar as diferentes mediações que marcam o complexo processo histórico do qual esse quadro é expressão. Em que pese a situação de crescimento da economia brasileira e da massa de remuneração da força de trabalho, o que sobressai predominantemente, como significativas demandas do capital relativas à educação, é tanto a redução dos custos do trabalho ${ }^{32}$ quanto um elenco de requerimentos elementares de formação.

Ao realizar a projeção da necessidade de qualificação da classe trabalhadora para os próximos três anos, o Serviço Nacional de Aprendizagem Industrial (SENAI) a secciona como um conjunto de peças a se encaixar no jogo do capital:

$52 \%$ será de técnicos com formação mais básica (com duração de até 200 horas, nas áreas eletroeletrônica, metalmecânica, construção civil e automotiva), 26\% de técnicos com mais de 200 horas de qualificação, 19\% de profissionais com formação técnica de nível médio e 3\% de pessoas com ensino superior. (Um mapa..., 2011)

A face real da demanda expressa os patamares da pirâmide educacional desejada pelo capital industrial, que ainda está assentada, predominantemente, nos níveis mais baixos de escolaridade e de formação profissional, em que encontramos as diferentes formas do trabalho simples.

Tal projeção coaduna-se com outras que são apresentadas pela CNI no documento “Um mapa do emprego no Brasil", também divulgado em 2011 (idem), em que merece ser destacado o fato de que a única previsão de crescimento da indústria, em nível nacional, é verificada nos setores da construção civil e da alimentação. Com relação a tais projeções, cabe destacar, no caso da construção civil, o fato de que estudo desenvolvido pela Fundação Getúlio Vargas (FGV,2011) evidencia ser esse um dos setores de menor requerimento de educação profissional, seja no nível da qualificação, seja no nível dos cursos técnicos ou mesmo de graduação tecnológica.

Não é outra a lógica que preside a oferta dos cursos de formação profissional do programa recém-criado pelo governo federal, o PRONATEC. A análise do Guia PRONATEC de cursos FIC (Brasil.MEC/SECAD, [2011]) indica os seguintes

32 Segundo o Instituto de Pesquisa Econômica Aplicada (IPEA) (Redução..., 2011, p. 8) "a redução da pobreza e da desigualdade no Brasil ainda se assenta sobre bases frágeis, pois foi puxada pela oferta de empregos de baixa remuneração no setor de serviços e comércio". Segundo o estudo do órgão federal, "dos 2,1 milhões de novos postos de trabalho criados por ano na década de 2000, 95\% pagavam até 1,5 salário mínimo $(\mathrm{R} \$ 817,5)$ ", o que se deve, "em larga escala, à redução dos postos de trabalho no setor industrial e ao crescimento de vagas no setor de serviços". 
percentuais de ofertas de cursos por carga horária mínima: os cursos de $160 \mathrm{~h}$ correspondem a $70 \%$ do total de ofertas; os restantes 30\% dessa oferta estão distribuídos entre cursos com cargas horárias entre $180 \mathrm{~h}$ e $500 \mathrm{~h}$, com destaque para as ofertas com $200 \mathrm{~h}$, correspondendo a $11 \%$ do total, e para as com $240 \mathrm{~h}$, correspondentes a $4,5 \%$ do total. Importante sublinhar, também, que das 443 ofertas formativas apresentadas, 326 requerem, tão somente, o ensino fundamental incompleto e 67 exigem o ensino fundamental completo. No que concerne a exigências no nível do ensino médio, 23 são destinadas àqueles que possuem esse nível incompleto e 22 aos que o concluíram. ${ }^{33}$

A análise dos dados coletados no decorrer das pesquisas nos permite afirmar que as demandas do capital e as ofertas formativas promovidas pelo Estado para a classe trabalhadora convergem, de forma clara, no sentido axiológico. Os percursos variados e flexíveis aqui apresentados, na realidade, redefinem a dualidade educacional, conferindo-lhe novos processos de destituição de direitos que reafirmam sua marca social.

Cabe ressaltar, nesta conclusão, que a tese do desenvolvimento desigual e combinado, orientadora da análise, não é antagônica à dualidade educacional de novo tipo, como aqui a denominamos. Entendemos, ao contrário, que o desenvolvimento desigual e combinado constitui uma manifestação do modo de produção capitalista, que se assenta na dualidade estrutural enquanto expressão do antagonismo capital-trabalho. A dualidade educacional (em suas diferentes formas históricas) representa, assim, tão somente uma manifestação histórica desse antagonismo, que não será superado nos marcos do capitalismo.

$\mathrm{Na}$ análise se evidencia também o fato de que a totalidade capital constitui em sua gênese, e não deixará de constituir, uma potência expropriadora que fundamenta a subordinação permanente, intensa e extensa da força de trabalho. É necessário ressaltar, porém, embora não tenhamos desenvolvido essa argumentação nos limites deste artigo, que essa totalidade não é homogênea e se constrói por processos históricos diversos, híbridos e atravessados por contradições. É no seio dessa construção social contraditória que devem ser compreendidas as particularidades do Brasil no âmbito educacional. Deve-se sublinhar, ainda, que a centralidade da contradição não elide a evidência teórico-metodológica de que a anatomia da estrutura educacional só pode ser plenamente compreendida à luz da economia política. ${ }^{34}$

Se, por um lado, o pessimismo da razão não permite elidir, na análise, o quadro delineado neste trabalho, por outro, as contradições inerentes a todos os fatos sociais e o otimismo da vontade nos obrigam a trazer, ainda que brevemente, as formas como a resistência da classe trabalhadora, embora cada vez mais pulverizada, se fazem presentes nos embates político-ideológicos que marcam sua educação. Nesse sentido, não podemos ignorar que diferentes formas dessas

33 Duas ofertas formativas não especificam o nível de escolaridade requerido.

34 Acerca das acepções de economia política e da utilização marxiana da expressão, ver, por exemplo, Teixeira (2000). 
resistências operam num cenário de correlações de forças que, embora bastante desfavorável, apontam para a construção de alternativas que visam à educação integral da classe trabalhadora.

Entre tais alternativas, destacamos brevemente, a título de exemplo, a forma como os trabalhadores vinculados aos movimentos sociais do campo - em que se destaca o Movimento dos Trabalhadores Rurais Sem Terra (MST) - se apropriaram do PRONERA, ampliando suas ofertas e reconfigurando, a seu favor, seus contornos e propostas, o que também ocorreu com algumas experiências do Brasil Alfabetizado. Mesmo no âmbito do PLANFOR, algumas frações da classe trabalhadora não se conformaram aos limites dessa política de governo para fazer jus aos recursos disponíveis e avançaram teórica e metodologicamente no que concerne à EJA trabalhadores com os Programas Integrar e Integração.

É necessário, também, assinalar que o acúmulo de reflexões e propostas acerca da educação da classe trabalhadora, construído em conjunto com intelectuais comprometidos com a educação politécnica, unitária e capaz de assegurar uma formação integral aos trabalhadores, constituiu elemento fundamental para a atual existência do PROEJA, embora seja bastante limitado o seu alcance e conviva com alternativas que com ele não se coadunam, como é o caso do PROJOVEM Urbano (cuja precariedade aparentemente contradiz a amplitude das metas estabelecidas pelo governo).

As lutas e acúmulos aí implicados, no entanto, têm sido permanentemente tensionadas e, não raramente, contidas ou atenuadas por ofensivas que envolvem desde a instituição de novos projetos afirmadores da perspectiva hegemônica até diversificadas tentativas de apropriação e transformismo de projetos originalmente constituídos em uma perspectiva antagônica. Exemplo disso é a forma como a proposta do ensino integrado, enquanto formulação historicamente determinada e transitória, visando à educação integral, vem sendo transmutada pelo capital, que ignorando seu horizonte emancipador vem transformando a própria expressão ensino integrado em rótulo para uma formação funcionalista, subordinada à lógica do mercado e formadora de trabalhadores aos quais se busca destituir a possibilidade de crítica ativa e organização coletiva.

Sabemos, todos, que é essencial reconhecer os limites e as possibilidades reais de atuação, dimensionando efetivamente cada iniciativa e o conjunto da luta, num cenário que não pode deixar de ser compreendido como adverso, apesar dos avanços que movem a história. Para tanto, pretendemos contribuir trazendo neste trabalho a análise geral das duas últimas décadas, em que se evidencia que a fragmentação da educação, como expressão da fragmentação imposta à própria existência humana, concorre de forma bastante significativa para que no âmbito do capital-imperialismo a reprodução das classes sociais se mantenha intocada, apesar de suas novas configurações, como convém à atual ordem capitalista. 


\section{REFERÊNCIAS}

Algebaile, Eveline. Escola pública e pobreza no Brasil: a ampliação para menos. Rio de Janeiro: FAPERJ; Lamparina, 2009.

Antunes, Ricardo. O caracol e sua concha. São Paulo: Boitempo, 2005.

Brasil.MEC/SECAD. Guia PRONATEC de cursos FIC. [S.1.: s.n., 2011].

Conferação Nacional da Indústria - CNI. Mapa estratégico da indústria 2007-2015. Brasília: CNI/DIREX, 2005. Disponível em: <http://www.cni.org.br >. Acesso em: 15 maio 2011.

Coutinho, Carlos Nelson. A democracia como valor universal e outros ensaios. Rio de Janeiro: Salamandra, 1984.

FAchin, Patricia. A democracia transformada pelas redes sociais: entrevista com Ronaldo Lemos. Observatório da Imprensa [on-line], ed. 655, 15 ago. 2011. Disponível em: <http:// www.observatoriodaimprensa.com.br/news/view/a-democracia-transformada-pelasredes-sociais>. Acesso em: 14 set. 2011.

Fernandes, Florestan. As mudanças sociais no Brasil.In: Ianni, Octavio (Org.). Florestan Fernandes: sociologia crítica e militante. São Paulo: Expressão Popular, 2007. p. 221-272. . Sociedades de classes e subdesenvolvimento. São Paulo: Global, 2008.

Fontes, Virgínia. A política e a arte da desqualificação.In: Reflexões im-pertinentes: história e capitalismo contemporâneo. Rio de Janeiro: Bom Texto, 2005. p. 271-316.

. O Brasil e o capital-imperialismo. Teoria e história. Rio de Janeiro: FIOCRUZ/ UFRJ Editora, 2010.

Frigotto, Gaudêncio. A produtividade da escola improdutiva: um (re)exame das relações entre educação e estrutura econômico-social e capitalista. São Paulo: Cortez, 1984.

Fundação Getúlio Vargas - FGV. Centro de políticas sociais. Trabalho, educação e juventude na construção civil. Rio de Janeiro: FGV/CPS, 2011. Disponível em: <http:// cps.fgv.br/construcao>. Acesso em: 20 set. 2011.

Gramsci, Antonio. Introdução ao estudo da filosofia. A filosofia de Benedetto Croce. Rio de Janeiro: Civilização Brasileira, 1999. (Cadernos do Cárcere, v. 1).

. Maquiavel. Notas sobre o Estado e a política. Rio de Janeiro: Civilização Brasileira, 2000a. (Cadernos do Cárcere, v. 3).

Os intelectuais. O princípio educativo. Jornalismo. Rio de Janeiro: Civilização Brasileira, 2000b. (Cadernos do Cárcere, v. 2).

Manacorda, Mario A. Marx e a pedagogia moderna. São Paulo: Cortez, 1991.

MontaÑo, Carlos. Terceiro setor e questão social: crítica ao padrão emergente de intervenção social. São Paulo: Cortez, 2002.

Oliveira, Francisco de. Crítica à razão dualista. O ornitorrinco. São Paulo: Boitempo, 2003.

Puiggrós, Adriana; Gagliano, Rafael (Dir.). La fábrica del conocimiento. Los saberes socialmente productivos en América Latina. Argentina: Homo Sapiens, 2004. 
Redução da desigualdade ainda é frágil, alerta IPEA. Folha de S. Paulo, São Paulo, 5 ago. 2011. Disponível em: <http://www1.folha.uol.com.br/poder/954883-reducao-dadesigualdade-ainda-e-fragil-alerta-ipea.shtml>. Acesso em: 12 set. 2011.

Rodrigues, José. O moderno principe industrial: o pensamento pedagógico da Confederação Nacional da Indústria. Campinas: Autores Associados, 1998.

Rummert, Sonia Maria. Educação e identidade dos trabalhadores. As concepções do capital e do trabalho. São Paulo; Niterói: Xamã; Intertexto, 2000.

A modernização conservadora como marca da educação de jovens e adultos trabalhadores no Brasil. In: ___ _ CanÁrio, Rui; Frigotto, Gaudêncio (Org.). Políticas de formação de jovens e adultos no Brasil e em Portugal. Niterói: EdUFF, 2009. v. 1, p. 213-232.

Suchodolski, Bogdan. Teoria marxista da educação. In: Wojnar, Irena; Mafra, Jason F. (Org.). Bogdan Suchodolski. Recife: Fundação Joaquim Nabuco; Massangana, 2010. p. 51-88.

Teixeira, Aloísio. Marx e a economia política: a crítica como conceito. Econômica, Niterói, n. 4, p. 85-109, 2000.

Ventura, Jaqueline Pereira. Educação de jovens e adultos ou educação da classe trabalhadora? Concepções em disputa na contemporaneidade brasileira. 2008. 302f. Tese (Doutorado em Educação) - Universidade Federal Fluminense, Niterói, 2008.

Um mapa do emprego no Brasil. Revista Época [on-line], Rio de Janeiro: Editora Globo, 18 mar. 2011. Disponível em: <http://revistaepoca.globo.com/Revista/Epoca /0,,EMI219290-15259,00.html>. Acesso em: mar. 2012.

\section{SOBRE AS AUTORAS}

Sonia Maria Rummert é doutora em educação pela Pontifícia Universidade Católica do Rio de Janeiro (PUC-Rio). Professora associada da Universidade Federal Fluminense (UFF).

E-mail: rummert@uol.com.br

Eveline Algebaile é doutora em educação pela Universidade Federal Fluminense (UFF). Professora adjunta da Universidade do Estado do Rio de Janeiro (UERJ).

E-mail: ealgebaile@gmail.com

Jaqueline Ventura é doutora em educação pela Universidade Federal Fluminense (UFF). Professora adjunta da mesma instituição.

E-mail: jaqventura@uol.com.br 


\section{SONIA MARIA RUMMERT, EVELINE ALGEBAILE E JAQUELINE VENTURA}

\section{Educação da classe trabalhadora brasileira: expressão do desenvolvimento desigual e combinado}

O objetivo deste artigo é explicitar o efetivo sentido e o caráter funcional do compósito constituído, na atualidade brasileira, por expressivo conjunto de iniciativas voltadas para a educação e a formação da classe trabalhadora. Para atingir o objetivo proposto, apresentamos considerações acerca dos conceitos de capital-imperialismo e de desenvolvimento desigual e combinado, bem como de suas expressões no Brasil e, em particular, na educação e formação da classe trabalhadora. Procura-se, assim, evidenciar como no cenário do capital-imperialismo subalterno são gestadas novas formas de destituição do direito de acesso universal ao conhecimento científico e tecnológico. Finalmente, abordamos o conjunto de programas e ações empreendidos pelo governo federal, a partir da década de 1990, apresentando-os reunidos segundo características que identificamos portadoras de similitudes.

Palavras-chave: educação da classe trabalhadora; políticas de educação no Brasil; trabalho e educação.

\section{Education of the Brazilian working class: an expression of uneven and combined development}

The purpose of this article is to make explicit the actual meaning and the functional character of the composite constituted by an expressive set of initiatives for education and the training of the working class in Brazil today. To reach that goal, we present considerations about the concepts of capital-imperialism and uneven and combined development, as well as their expressions in Brazil, especially in the education and training of the working class. Thus, we seek to evidence how new forms of removal of the right to universal access to scientific and technological knowledge are generated in the scenario of subaltern capital-imperialism. Finally, we address the set of programs and actions undertaken by the federal government since the 1990s, which we have assembled according to their similarities.

Keywords: education of the working class; education policies in Brazil; work and education.

\section{Educación de la clase trabajadora brasileña: expresión del desarrollo desigual y combinado}

El propósito de este artículo es explicitar el efecto de sentido y el carácter funcional de la composición constituida hoy, en Brasil, por el expresivo conjunto de iniciativas dirigidas a la educación y formación de la clase trabajadora. Para alcanzar los fines del análisis propuesto, presentamos consideraciones respecto a los conceptos de capitalimperialismo y desarrollo desigual y combinado, asi como de sus expresiones en Brasil y, particularmente, en la educación y formación de la clase trabajadora. De esa manera, se 
intenta evidenciar cómo se gestan, en el escenario del capital-imperialismo subalterno, nuevas formas de destitución del derecho al acceso universal al conocimiento cientifico y tecnológico. Finalmente, examinamos el conjunto de programas y acciones emprendidas por el gobierno federal, desde la década de 1990, y los presentamos reunidos de acuerdo a las características identificadas como portadoras de similitudes.

Palabras clave: educación de la clase trabajadora; politicas de educación en Brasil; trabajo y educación. 